\author{
Beata Gracz*, Janusz Lelito**, Paweł Żak*, Witold K. Krajewski***, \\ Józef S. Suchy****, Michał Szucki*
}

\title{
STATISTICAL ANALYSIS OF SiC ADDITION ON HETEROGENEOUS NUCLEATION OF $\alpha$-Mg PRIMARY PHASE IN THE AZ91/SiC COMPOSITE
}

\section{INTRODUCTION}

Composites based on magnesium alloys are among the fastest developing materials. Unique combination of low density with good strength and corrosion resistance result in more frequent and more extensive use of magnesium alloy as a structural lightweight material in automotive, aerospace and IT industry.

One of the main characteristics that determine the mechanical properties of composite is the primary phase grain size. There are many publications that show the usefulness of the $\mathrm{SiC}$ as a potent inoculant for heterogeneous nucleation of magnesium primary phase in the AZ91/SiC composites [1-5]. This study introduces a statistical analysis of the SiC particles addition effect on the nucleation process of $\alpha-\mathrm{Mg}$ primary phase.

\section{RESEARCH METHOD}

\subsection{Composite casting}

Composite preparation process consisted of two stages. First the AZ91 alloy was melted as a matrix for the tested composites. Then pre-heated particles of $\mathrm{SiC}$ were put into the liquid AZ91 alloy and were mixed together. Different amount of ceramic particles of different size was used. The chemical composition of metal matrix alloy is shown in Table 1.

* M.Sc., ** Ph.D., *** Ph.D., D.Sc., **** Prof., Ph.D., D.Sc.: Faculty of Foundry Engineering, AGH University of Science and Technology, Kraków, Poland; e-mail: gracz@agh.edu.pl 
Table 1. Chemical composition of AZ91 alloy

\begin{tabular}{|c|c|c|c|c|c|c|c|c||}
\hline \multicolumn{10}{|c||}{ Chemical composition, wt. \% } \\
\hline $\mathrm{Al}$ & $\mathrm{Zn}$ & $\mathrm{Mn}$ & $\mathrm{Si}$ & $\mathrm{Cu}$ & $\mathrm{Fe}$ & $\mathrm{Ni}$ & $\mathrm{Be}$ & $\mathrm{Mg}$ \\
\hline 8.5 & 0.64 & 0.23 & 0.03 & 0.003 & $<0.002$ & 0.001 & $10 \mathrm{ppm}$ & rest \\
\hline
\end{tabular}

The second stage was casting such prepared composites into standard thermoanalysis croning sand cup with thermocouple K type. Samples differs in reinforcement particles size (A-10, B-40, C-76 $\mu \mathrm{m})$ and content $(0.06,0.5,1.0,2.0,3.5 \mathrm{wt}$. \%). The exact parameters of the process are shown in Table 2.

Table 2. Parameters of $\mathrm{AZ} 91 / \mathrm{SiC}$ sample preparation process

\begin{tabular}{|c|c|c|c||}
\hline Casting symbol & A & B & C \\
\hline SiC particles size, $\mu \mathrm{m}$ & 10 & 40 & 76 \\
\hline AZ91 mass, $\mathrm{g}$ & 5960 & 6250 & 5800 \\
\hline Ambient temperature, ${ }^{\circ} \mathrm{C}$ & 22 & 22 & 22 \\
\hline SiC particles temperature, ${ }^{\circ} \mathrm{C}$ & 320 & 320 & 320 \\
\hline In-mould temperature, ${ }^{\circ} \mathrm{C}$ & 100 & 100 & 100 \\
\hline Stirring time, $\mathrm{s}$ & 240 & 180 & 180 \\
\hline
\end{tabular}

\subsection{Grain diameter measurement}

Polished samples were etched for 80-95 s [5-6]. Chemical composition of etching solution is shown in Table 3.

Table 3. Chemical composition of etchant for AZ91/SiC composite [5-6]

\begin{tabular}{|c|c|c|c|}
\hline Component & Distilled Water & Ethanol & Acetic Acid \\
\hline Amount, $\mathrm{ml}$ & 50 & 150 & 1 \\
\hline
\end{tabular}

After this treatment it was possible to distinguish dendritic grains on the specimen surface. For this study an optical microscope Carl Zeiss AXIO Imager.A1 with cross polarized light and $\lambda$ filter was used. Metallographic examination was performed. Figure 1 shows the microstructural changes with increasing $\mathrm{SiC}$ content. The grains were counted and their diameters were measured. 


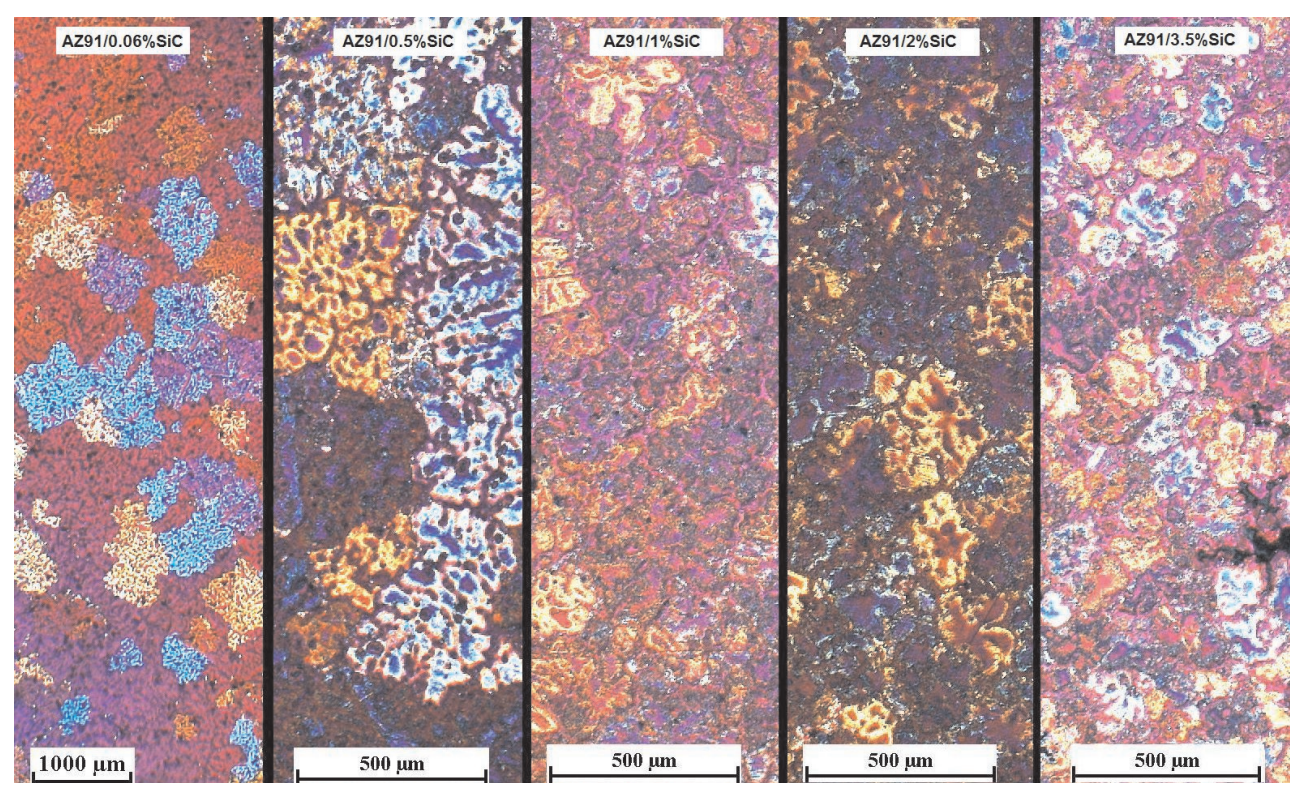

Fig. 1. Micrographs of AZ91/SiC composites with increasing SiC content

\section{RESULTS AND DISCUSSION}

From metallographic analysis of grain distribution series of values were obtained. Analysis and verification of received data were made using the Gaussian normal distribution. Results of the statistical analysis are tabulated (Tab. 4-5). The bell curves were drawn (Fig. 2-5) which made it possible to estimate how $\mathrm{SiC}$ affects nucleation of $\alpha-\mathrm{Mg}$ phase in easy way.

In the first step specimens with different size of $\mathrm{SiC}$ particles were compared (Tab. 4). Mean diameter was taken as the characteristic dimension of grains.

Table 4. The mean diameter of grains $(d)$ and the standard deviation (SD) for specimens with $1 \mathrm{wt}$ \% of $\mathrm{SiC}$

\begin{tabular}{|c|c|c|c|}
\hline Casting symbol & SiC particles size, $\mu \mathrm{m}$ & $d, \mu \mathrm{m}$ & $\mathrm{SD}, \mu \mathrm{m}$ \\
\hline A & 10 & 128.488 & 35.278 \\
\hline B & 40 & 210.250 & 61.041 \\
\hline C & 76 & 377.999 & 106.719 \\
\hline
\end{tabular}

Results of the analysis were shown in Figure 2. 
a)

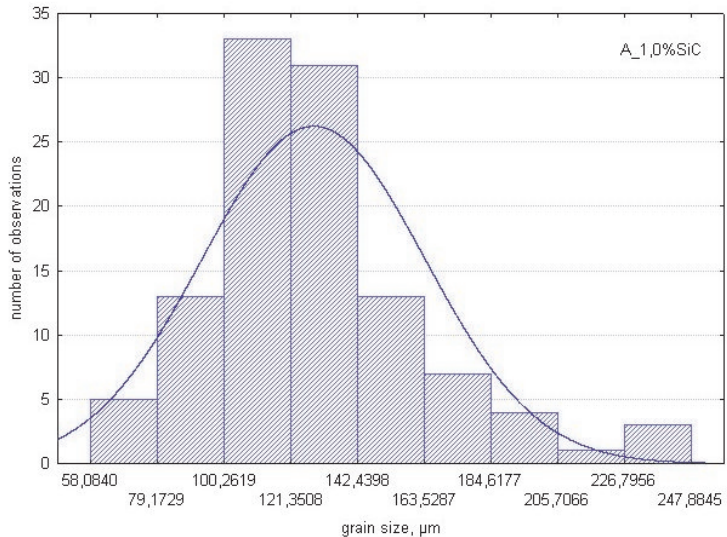

b)

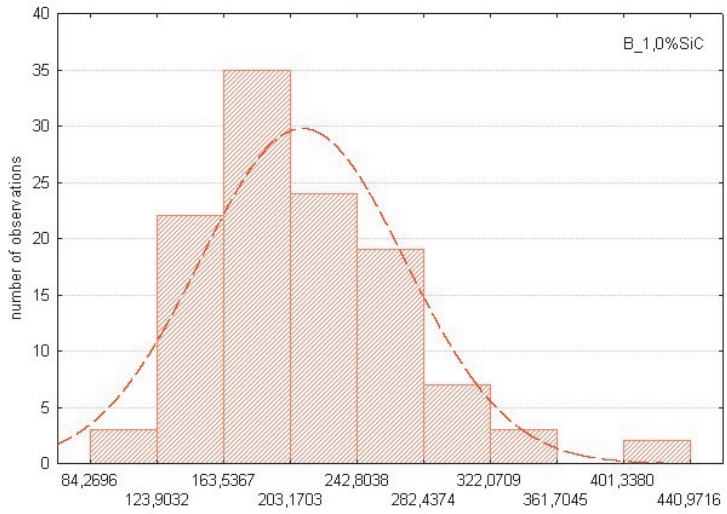

c)

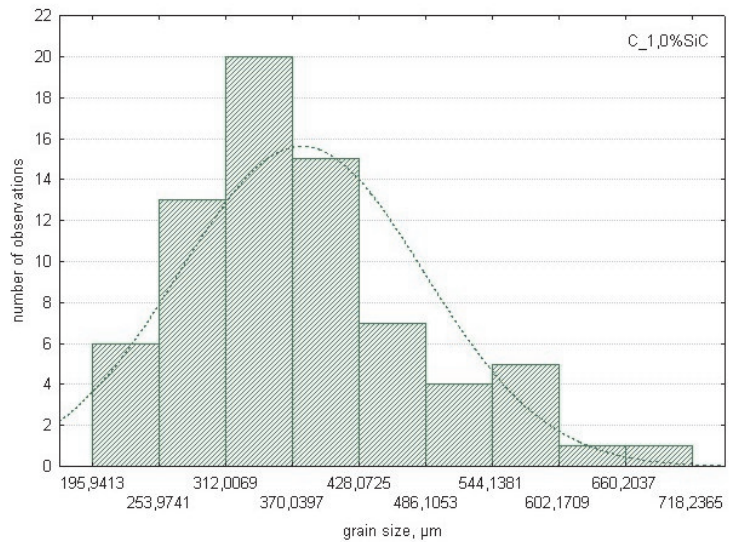

Fig. 2. Histogram of $\alpha-M g$ grain size with run of normal distribution for 1 wt. \% of SiC particles: a) $10 \mu \mathrm{m}$; b) $40 \mu \mathrm{m}$; c) $76 \mu \mathrm{m}$

Positive effect of $\mathrm{SiC}$ as inoculant depends on the $\mathrm{SiC}$ particles size. Mentioned observation is shown in Figure 3. 


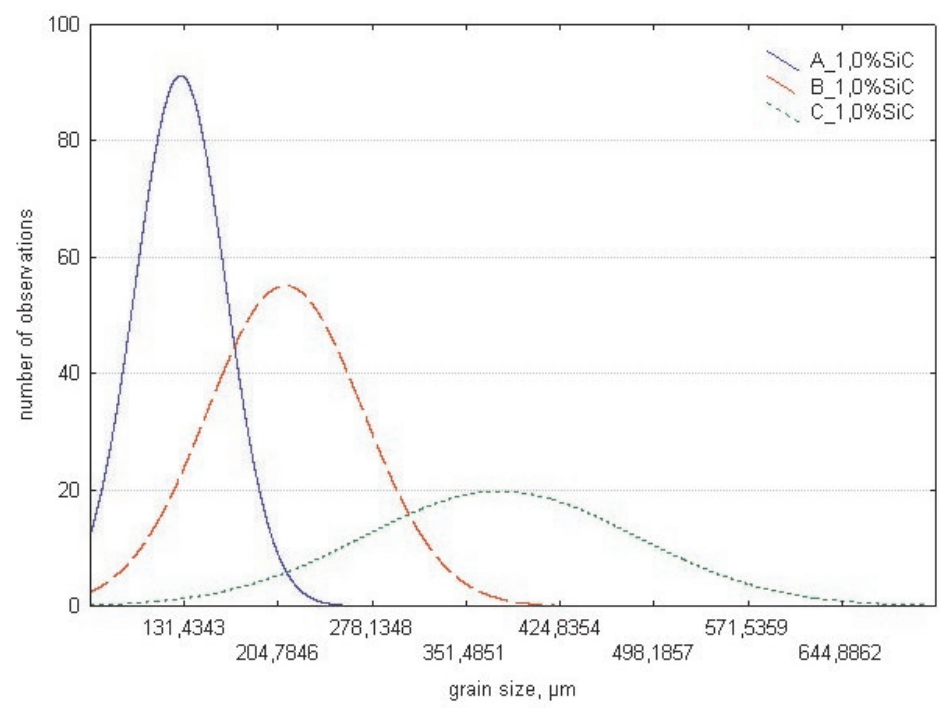

Fig. 3. Run of bell curves for $1 \mathrm{wt}$. \% of SiC and different size of SiC particles: $A-10 \mu \mathrm{m}, B-40 \mu \mathrm{m}$, $C-76 \mu m$

With the increase of $\mathrm{SiC}$ particles size, the maximum of the bell curve moves to the right. It means that with increasing of $\mathrm{SiC}$ particles size, the $\alpha-\mathrm{Mg}$ average grain size increase. Also coarse structure leads to decreasing the strength properties of composite. With the increasing of particle size also the standard deviation increasing. The bell curve for $1 \mathrm{wt}$ \% of $76 \mu \mathrm{m}$, as it is can be seen in Figure 3, is flattened which suggesting a great diversity of $\alpha-\mathrm{Mg}$ grain size.

The second stage of analysis was to compare the data for the composites with different contents of a reinforcing phase (Tab. 5).

Table 5. The mean diameter of grains $(d)$ and the standard deviation (SD) for specimens with $40 \mu \mathrm{m}$ $\mathrm{SiC}$ particles size

\begin{tabular}{|c|c|c|}
\hline Contents of SiC, wt. $\%$ & $d, \mu \mathrm{m}$ & SD, $\mu \mathrm{m}$ \\
\hline 0.06 & 566.249 & 208.693 \\
\hline 0.24 & 528.943 & 161.746 \\
\hline 0.5 & 388.689 & 145.614 \\
\hline 1.0 & 210.250 & 61.041 \\
\hline 2.0 & 190.094 & 60.627 \\
\hline 3.5 & 113.018 & 28.988 \\
\hline
\end{tabular}

Effect of $\mathrm{SiC}$ particles on the $\alpha-\mathrm{Mg}$ grain size depends on ceramic particles content. This feature is illustrated in Figure 4.

Results of this effect comparison were shown in Figure 5. 
a)

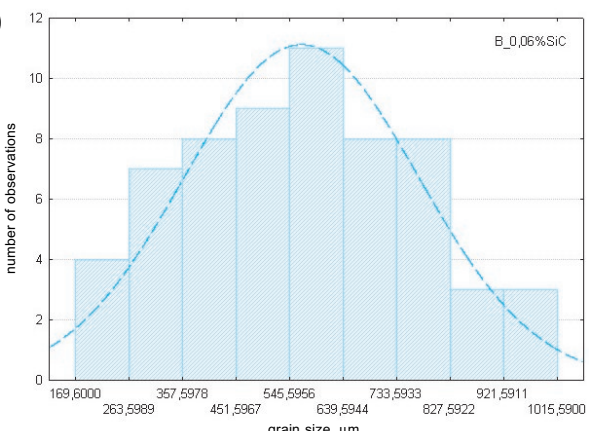

b)

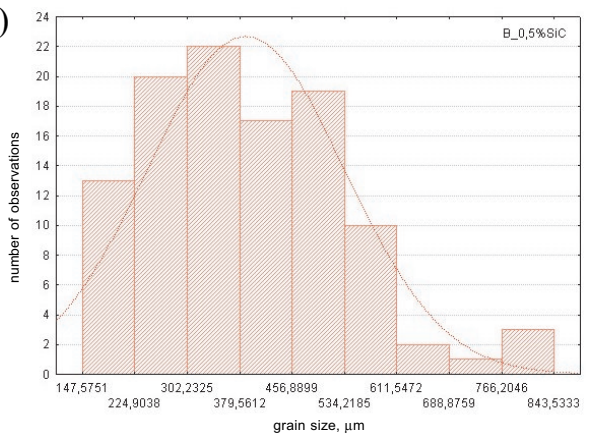

c)

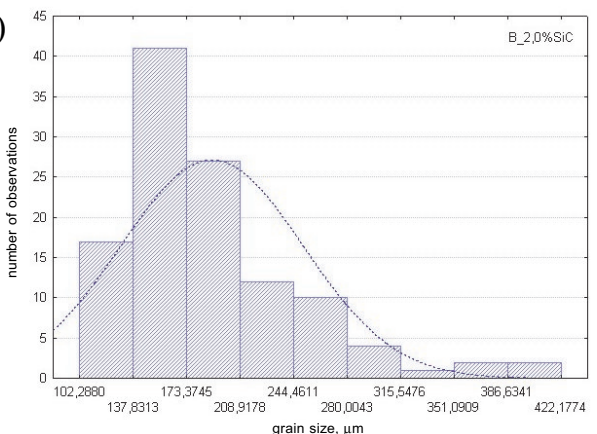

d)

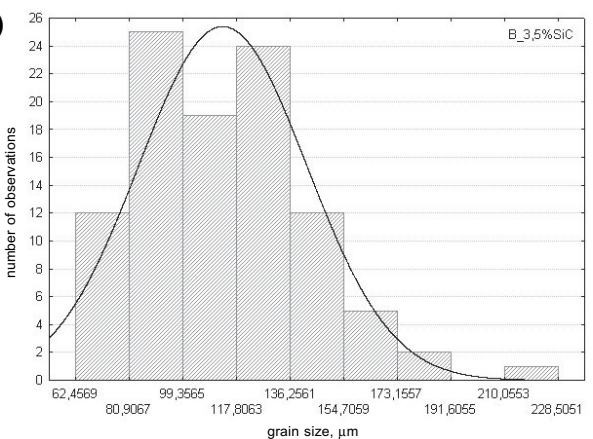

Fig. 4. Histogram of $\alpha$-Mg grain size with run of a normal distribution for: a) $0.06 \mathrm{wt} \%$; b) $0.5 \mathrm{wt} . \%$; c) $2 \mathrm{wt} \%$; d) $3.5 \mathrm{wt} \%$ of $40 \mu \mathrm{m} \mathrm{SiC} \mathrm{particles}$ 
With the increase of $\mathrm{SiC}$ content in the composite the maximum of the bell curve move to the left and curve is more and more sharp. The shape of the curves (Fig. 5) proves that with the increasing of reinforcing phase content the average grain size of $\alpha-\mathrm{Mg}$ phase decreases and the differences between the size of individual grains are getting smaller.

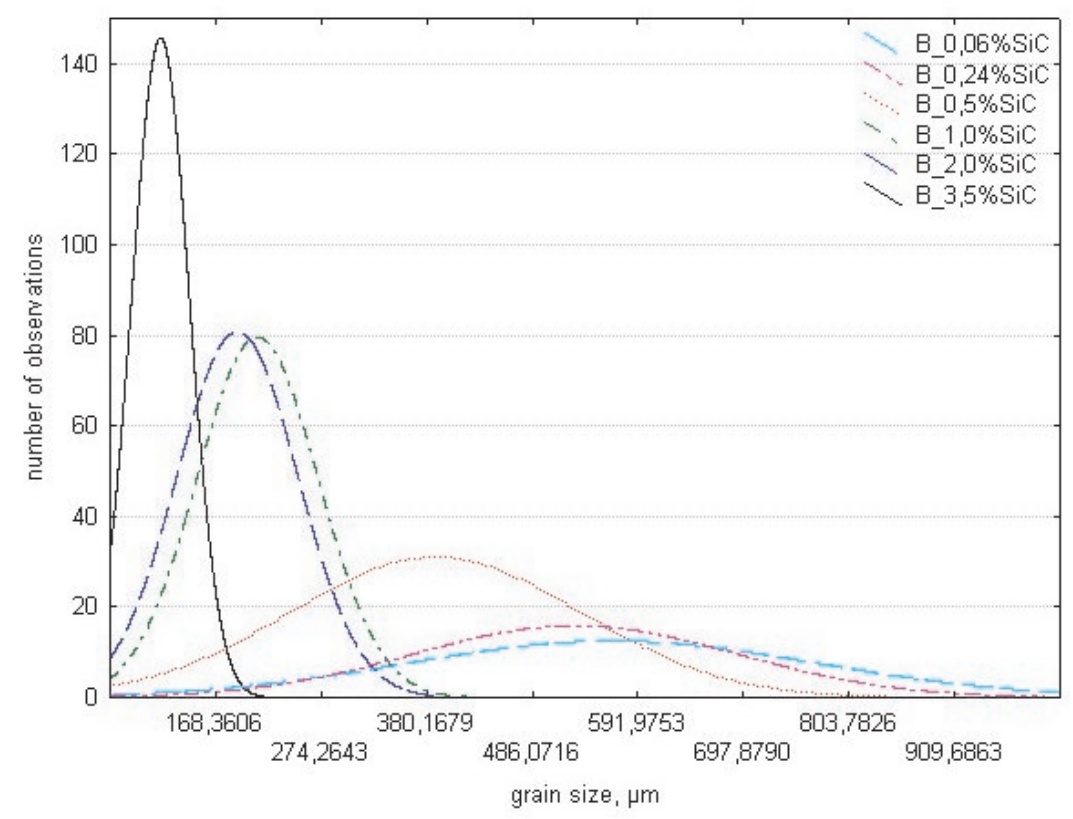

Fig. 5. Run of bell curves for $40 \mu \mathrm{m}$ of SiC particles size and different contents of $\mathrm{SiC}(0.06,0.24,0.5$, 1.0, 2.0, $3.5 w t . \%)$

\section{CONCLUSIONS}

The increase in content of $\mathrm{SiC}$ particles causes reduction of $\alpha-\mathrm{Mg}$ grain size and reduction of differences between sizes of individual grains.

Smaller particles of $\mathrm{SiC}$ made it possible to achieve finer microstructure and increase in homogenization of grain size.

Future research should focus on defining the optimal content and size of reinforcing phase for AZ91/SiC composite, taking both mechanical properties and economy of the manufacturing process into consideration.

\section{Acknowledgements}

The authors acknowledge The European Community for financial support under Marie Curie Transfer of Knowledge grant No. MTKD-CT-2006-042468 (AGH No. 27.27.170.304) 


\section{REFERENCES}

[1] Cai Y., Tan M.J., Shen G.J., Su H.Q.: Microstructure and heterogeneous phenomena in cast SiC particles reinforced magnesium composite, Materials Science and Engineering A282, 2000, 232-239

[2] Luo A.: Heterogeneous nucleation and grain refinement in cast $\mathrm{Mg}(\mathrm{AZ} 91) / \mathrm{SiC}$ metal matrix composites, Canadian Metallurgical Quarterly 1996, 35, 375-383

[3] Lelito J., Żak P., Suchy J.Sz.: The grain nucleation rate of AZ91/SiC composite based on Maxwell-Hellawell model, Archives of Metallurgy and Materials 2009, 54(2), 347-350

[4] Gracz B., Żak P., Lelito J., Krajewski W.: Statistical analysis of grain size distribution for different AZ91/ $\mathrm{SiC}$ composites, 7th International PhD Foundry Conference, Brno 2010 - conference proceedings

[5] Żak P., Lelito J., Suchy J.Sz., Krajewski W., Krawiec H., Haberl K., Shumacher P., Greer L., Shirzadi A., Gracz B.: Modeling the effect of $\mathrm{SiC}$ particie size on crystallization of magnesium metal matrix composite AZ91/SiC, Inżynieria materiałowa No. 3 (175) May-June 2010, SIGMA-NOT Sp. z o.o., Warszawa 2010, 703-707

[6] Maltais A., Dube D., Roy F., Fiset M.: Optical anisotropy of a color-etched AZ91 magnesium alloy, Materials Characterisation. 2005, Vol. 54, 315-326

Received

December 2010 